\title{
Correction to: The association between occupational categories and grip strength in Korean male workers
}

\author{
Kayoung Lee ${ }^{1}$ D \\ Published online: 12 February 2021 \\ ○) Springer-Verlag GmbH Germany, part of Springer Nature 2021
Correction to:
International Archives of Occupational and Environmental Health \\ https://doi.org/10.1007/s00420-020-01635-1
}

In the original Publication of the article, the funding information was incorrectly published. The correct publication should be "This work was funded by the National Research Foundation of Korea Grant funded by the Korean Government (NRF-2017S1A5B8066096)".

This has been corrected in this paper.

Publisher's Note Springer Nature remains neutral with regard to jurisdictional claims in published maps and institutional affiliations.

The original article can be found online at https://doi.org/10.1007/ s00420-020-01635-1.

Kayoung Lee

kayoung.fmlky@gmail.com

1 Department of Family Medicine, Busan Paik Hospital,

College of Medicine, Inje University, 75, Bokji-ro,

Busanjin-gu, Busan 47392, Republic of Korea 